\title{
An Inventory Model Considering All Unit Discount and Carbon Emissions
}

\author{
I.M. Kristiyani* and Y. Daryanto
}

\begin{abstract}
Consumer satisfaction is an essential factor in the ongoing business process. Companies must be able to meet consumer demands and to consider customers' concerns on price. In a supplier and customer relationship, a given discount will affect the order size. Besides, in the current developing industry, the business must consider environmental factors without disturbing. Recently, researchers and practitioners develop environmentally-friendly sectors so that the environment will be well managed and not polluted. For example, they can control carbon emissions by optimizing production operations and product distribution. This paper presents a study on the relationship between discount on the economic order quantity model and the total carbon emissions. This research develops a procurement model by considering an all-unit discount system and carbon emission tax. The aim is to determine the optimal order that minimizes the total cost.
\end{abstract}

Keywords: Inventory, EOQ Model, All Unit Discount, Carbon Emissions.

Article Info: Received June 20, 2020; Revised August 22, 2020; Accepted September 4, 2020.

\section{INTRODUCTION}

Various industries are developing rapidly. Thus it increases competition between companies in attracting customers. Companies should notice the needs and satisfaction of customers, both in terms of the quality and availability of goods. In this case, inventory is critical so that the distribution process of goods can run smoothly. Companies should manage the inventory properly because it relates to the costs that be incurred in maintenance. Therefore, they must control the stock by determining the right amount to comply with the demand for an item.

A discount is frequently met in the market system. The supplier can attract customers by offering discounts to buyers. Some types of deals that can be given are all-unit discount, incremental discount, or standard-quality discount (Taleizadeh \& Pentico, 2014). The discount can encourage buyers to increase the quantity or number of goods purchased. Buyers will be attracted to buy when the offered discount is big. However, the company should consider the given discount, which does not incur losses. Some previous studies have studied the inventory model by considering all unit discounts, namely Gupta (1988), José \& García-Laguna (2003), Djunaidi et al. (2005), Limansyah \& Lesmono (2011), and Taleizadeh \& Pentico (2014).

At this time, the industrial world must have an awareness to be eco-friendly not to cause global warming. Companies can make plans that consider the long-term impacts so they can contribute to reducing adverse environmental effects. Bonney and Jaber (2011) suggested good management of inventory considering emissions and waste. Transportation, warehousing, and raw materials storing produce carbon emissions. Emissions produced from vehicles depend on fuel consumption, the fuel emissions level, and the mileage (Daryanto et al., 2019). To reduce the carbon emissions, most companies focused on emission reduction in physical processes, such as replacing equipment and facilities that are inefficient in energy

I.M. Kristiyani* and Y. Daryanto are with the Department of Industrial Engineering, Faculty of Industrial Technology, Universitas Atma Jaya Yogyakarta (email: ika.murti@uajy.ac.id).

* Corresponding author 
consumption, redesigning products and packaging, distribution, and the use of energy sources that reduce pollution (Benjaafar et al., 2013; Chen et al., 2013). Some other studies considered carbon emissions in inventory management such as Hovelaque \& Bironneau (2015), Daryanto et al. (2019), Wang \& Ye (2018), and Wee \& Daryanto (2020).

In this research, an inventory model is developed by considering all unit discounts and carbon emissions to obtain a minimum total inventory cost. In previous literature studies, there has been no research that considers those two elements. Mathematical analysis through numerical examples and sensitivity analysis would be developed to test the results, namely, to determine the optimal order quantity with a minimum total inventory cost.

\section{LITERATURE REVIEW}

This section presents the theoretical background of this study.

\subsection{Inventory cost}

Tersine (1994) reviewed the economic order quantity (EOQ) inventory models. Traditionally, an EOQ model aims to determine the optimum order quantity to minimize the total inventory cost or maximize the total profit. According to Tersine (1994), the classical inventory cost consisted of four components, i.e., purchase costs, ordering costs (setup costs), storage costs (holding costs), and the cost of shortages (stockout costs). However, he accepted the possibility that inventory costs could be affected by other cost components. Costs that are incurred to purchase raw materials/goods is called purchase costs. This purchase costs can be affected by a discount. If the number of demands per year is known, then the purchase cost in a year is the product price per unit multiplied by the number of demands. The ordering cost is the cost incurred when an order is submitted. The amount of the ordering cost in one year is multiplicating the one-time ordering cost with the order frequency in one year. Storage costs may incur renting a place, insurance cost of the goods, electricity, maintenance, and other overhead expenses. Finally, in certain situations, there are stockout costs. It arises due to the organization has no inventory in stock.

Several studies separated transportation costs from the ordering cost, considering the contribution of transportation cost in the total distribution cost (Swenseth \& Godfrey, 2002). Gupta (1992) assumed that transportation cost became buyer responsibility. Bonney \& Jaber (2011) considered the carbon emissions cost from vehicle usage. Recently, Wangsa \& Wee (2020) incorporated transportation costs and all-unit discounts in a two-echelon supply chain inventory model.

\subsection{An inventory model with discounts}

EOQ is a simple inventory decision model and could be used as a basis for the development of other more complex models. Various inventory models were reviewed and developed by researchers. Some models have considered the presence of a price discount. Gupta (1988) developed a model for improving EOQ procedures by considering all unit discounts. José \& García-Laguna (2003) developed the EOQ model by considering backorders and all-units discounts. Djunaidi et al. (2005) examined the effect of raw material purchase planning with the EOQ model for multi items with all unit discounts. A discount is offered not only to attract customers. Djunaidi et al. (2005) revealed that the quantity discount or price discount could be used as an incentive for companies bought in larger quantities. Due to deals, the EOQ calculation would be modified. If a discount was applied to a purchase, the problem was determining the optimal order lot size associated with the purchase price to provide a minimum total storage cost. The economic order amount was calculated based on the total cost of inventory for each possible price and the minimum amount at which the price was applied. Limansyah \& Lesmono (2011) developed a multi-item inventory model by considering the expiry factor and all unit discount factor. Taleizadeh \& Pentico (2014) developed the EOQ model with a partial backorder and all-units discount.

\subsection{An inventory model with carbon emission costs}

To prevent global warming, companies should build eco-friendly industries. Companies can make plans that consider the long-term impacts, thereby contributing to reducing adverse environmental effects. In pursuing efforts to reduce carbon emissions, most companies had focused on emissions reduction from the physical processes. For example, they are replacing equipment and facilities that were not efficient in used energy, redesigning products, packaging, and distribution, and adoption of renewable energy sources (Chen et al., 2013; Benjaafar et al., 2013). Other researchers suggested good inventory management considering emissions and waste (Bonney \& Jaber, 2011; Kazemi et al., 2018; Tao \& Xu, 2019). Those studies added the cost of carbon emissions into the overall system cost based on carbon tax rules. In general, carbon tax acts as a penalty for industry because it produces emissions from its activities. Carbon emissions are generated from transportation, warehousing, and the storage process of raw materials.

In this research, an inventory model would be developed by considering all unit discounts and carbon emissions to develop the previous models. The state of the art of this study is shown in Table 1 presenting the comparison with previous studies.

\section{METHODOLOGY}

In an economic order quantity model with an allunit discount, a manufacturer or a retailer decides the optimum economic order quantity (EOQ) considering different price schedules offered by the supplier. This 
Table 1. State of the art of the research

\begin{tabular}{|c|c|c|c|}
\hline Author(s) & $\begin{array}{l}\text { All unit } \\
\text { discount }\end{array}$ & $\begin{array}{c}\text { Transportation } \\
\text { cost }\end{array}$ & $\begin{array}{r}\text { Carbon } \\
\text { emissions }\end{array}$ \\
\hline Gupta (1988) & Yes & & \\
\hline Jose \& García-Laguna (2003) & Yes & & \\
\hline Taleizadeh \& Pentico (2014) & Yes & & \\
\hline Limansyah \& Lesmono (2011) & Yes & & \\
\hline Djunaidi et al. (2005) & Yes & & \\
\hline Bonney \& Jaber (2011) & & Yes & Yes \\
\hline Hovelaque \& Bironneau (2015) & & Yes & Yes \\
\hline Daryanto et al. (2019) & & Yes & Yes \\
\hline Wee \& Daryanto (2020) & & Yes & Yes \\
\hline Wang \& Ye (2018) & & & Yes \\
\hline Wangsa \& Wee (2020) & Yes & Yes & \\
\hline This research & Yes & Yes & Yes \\
\hline
\end{tabular}

study assumes that the manufacturer works in a country implementing a carbon tax system and is willing to be greener. Hence, it considers both the discount price and carbon emission costs. Energy during inventory holding and fuel for transportation are counted as the sources of the emissions. Furthermore, this study follows the assumptions of the classical EOQ model in terms of constant demand patterns and price, no shortages, and an instantaneous replenishment.

The notations used in this inventory model are:

$Q \quad$ : Order quantity

$h \quad$ : Storage cost percentage per period

$w \quad$ : Average carbon emissions per unit in the warehouse

$D \quad$ : Number of goods requests per period

$S \quad$ : Order cost per cycle

$P_{i} \quad$ : The price per unit

$T C Q_{i} \quad:$ The total cost of inventory

$T E Q_{i} \quad$ : Total carbon emissions

$C_{p} \quad$ : Purchase costs during one planning period

$C_{o} \quad$ : Order costs for one planning period

$C_{s} \quad$ : Storage costs for one planning period

$C_{t} \quad$ : Transportation costs for one planning period

$E_{e} \quad$ : Power plant's standard emission

$F_{e} \quad:$ Fuel's standard emission

$T_{x} \quad$ : Carbon emission price or tax

$t_{f} \quad$ : Fixed costs for shipping goods

$d \quad$ : Mileage from the supplier

$c_{1} \quad:$ Fuel consumption when the vehicle is empty

$c_{2} \quad$ : Additional fuel consumption per unit load of transportation

$l \quad:$ Item weight

$t_{v} \quad:$ Variable costs for shipping goods

$e_{1} \quad$ : Cost of carbon emissions from vehicles; $e_{1=}$ $c_{1} \cdot F_{e} \cdot T_{x}$

$e_{2} \quad$ : Additional costs of carbon emissions from transportation of one item; $e_{2}=c_{2} \cdot l . F_{e} \cdot T_{x}$

\subsection{Model Development}

In this inventory model, there are discount factors and carbon emission costs that affect the total inventory cost. The total inventory cost is the sum of the purchase costs, ordering costs, storage costs, and transportation costs.

Purchase costs are costs incurred to buy goods. The supplier provides a discount schedule with the price of goods per unit is defined as follows (Gupta, 1988; Taleizadeh \& Pentico, 2014):

$P_{i}=\left\{\begin{array}{c}P_{0} \text { for }_{0} \leq Q \leq q_{1} \\ P_{1} \text { for }_{1} \leq Q \leq q_{2} \\ \cdots \\ P_{n} \text { for }_{n} \leq Q\end{array}\right.$

where $Q$ is order quantity, $P_{i}>P_{i+1}$, and $i=0,1,2,3$, $\ldots, n$ is the index for discount schedule.

If in a year there was a demand $D$ unit, then the total purchases cost in a year is a multiplication of item price per unit with demand quantity, namely

$C_{p}=P_{i} D$

Ordering cost is the charge incurred once an order is submitted. If the order costs were $S$, then the amount of the ordering cost in a year is multiplicating the one-time order cost with the order frequency in a year.

$C_{o}=\frac{S D}{Q_{i}}$

If the storage cost per unit of goods is stated at $h P i$ for a year, considering the average cost of carbon emissions in the warehouse, then

$$
\begin{aligned}
& C_{s}=\left(h P_{i}+w E_{e} T_{x}\right) \frac{Q_{i}}{2} \\
& C_{s}=\frac{Q_{i}}{2} h P_{i}+\frac{Q_{i}}{2} w E_{e} T_{x}
\end{aligned}
$$

When $T_{x}=0$, then equations (2), (3), and (4) are the same as Gupta (1988), which is the EOQ model with all-unit discount without considering carbon emissions.

Transportation cost consists of a fixed cost, some variable costs, and the cost of carbon emissions from vehicle usage (Wee \& Daryanto, 2020). Hence, the transportation cost per year is

$$
C_{t}=\frac{D}{Q_{i}}\left(t_{f}+\left(2 d c_{1} t_{v}+d c_{2} l Q_{i} t_{v}\right)+2 d e_{1}+d e_{2} Q_{i}\right)
$$

The total cost of inventory for one year is the total cost of purchase, order cost, storage cost, and transportation cost 


$$
\begin{aligned}
T C Q_{i}= & C_{p}+C_{o}+C_{s}+C_{t} \\
T C Q_{i}= & P_{i} D+\frac{S D}{Q_{i}}+\frac{Q_{i}}{2} h P_{i}+\frac{Q_{i}}{2} w E_{e} T_{x}+ \\
& \frac{D}{Q_{i}}\left(t_{f}+\left(2 d c_{1} t_{v}+d c_{2} l Q_{i} t_{v}\right)+\left(2 d e_{1}+d e_{2} Q_{1}\right)\right)
\end{aligned}
$$

From equation (7), we can obtain an equation to calculate the total carbon emissions $\left(T E Q_{i}\right)$ resulted from storage and transportation activities, namely:

$$
T E Q_{i}=\frac{Q_{i}}{2} w E_{e}+\frac{D}{Q_{i}}\left(2 d c_{1} F_{e}+d c_{2} l F_{e} Q_{i}\right)
$$

The minimum total inventory cost can be achieved if $\frac{\partial T C Q_{i}}{\partial Q_{i}}=0$, then:

$$
\begin{aligned}
& -\frac{S D}{Q_{i}^{2}}+\frac{1}{2} w E_{e} T_{x}-\frac{D t_{f}}{Q_{i}^{2}}-\frac{2 D d c_{1} t_{v}}{Q_{i}^{2}}-\frac{2 D d e_{1}}{Q_{i}^{2}}=0 \\
& -2 S D+h P_{i} Q_{i}^{2}+w E_{e} T_{x} Q_{i}^{2}-2 D t_{f}-4 D d c_{1} t_{v}-4 D d e_{1}=0 \\
& \left(h P_{i}+w E_{e} T_{x}\right) Q_{i}^{2}=2 S D+2 D t_{f}+4 D d c_{1} t_{v}+4 D d e_{1}
\end{aligned}
$$

or

$$
Q_{i}^{2}=\frac{2 S D+2 D t_{f}+4 D d c_{1} t_{v}+4 D d e_{1}}{h P_{i}+w E_{e} T_{x}}
$$

So, the optimal order quantity

$Q_{i}^{*}=\sqrt{\frac{2 S D+2 D t_{f}+4 D d c_{1} t_{v}+4 D d e_{1}}{h P_{i}+w E_{e} T_{x}}}$

To get $Q i$, we must prove the concavity of the total cost function. By using the first and second derivatives of TCQi against $Q i$, one has

$$
\begin{aligned}
& \frac{\partial T C Q_{i}}{\partial Q_{i}}=-\frac{S D}{Q_{i}^{2}}+\frac{1}{2} h P_{i}+\frac{1}{2} w E_{e} T_{x}-\frac{D t_{f}}{Q_{i}^{2}}-\frac{2 D d c_{1} t_{v}}{Q_{i}^{2}}-\frac{2 D d e_{1}}{Q_{i}^{2}} \\
& \frac{\partial^{2} T C Q_{i}}{\partial Q_{i}^{2}}=\frac{S D}{Q_{i}^{3}}+\frac{D t_{f}}{Q_{i}^{3}}+\frac{2 D d c_{1} t_{v}}{Q_{i}^{3}}+\frac{2 D d e_{1}}{Q_{i}^{3}}
\end{aligned}
$$

Because all parameter values are positive for $Q i>0$, equation (10) is always positive. Therefore, the total cost function is concave upwards.

\subsection{Model Validation}

The inventory model that has been obtained is validated to find out whether the model is correct. This validation is done by entering the values of $T_{x}=0, t_{f}=$ $0, t_{v}=0$ and $e_{1}=0$, i.e. there is no effect of carbon emissions. The equation for $Q$ becomes:

$$
Q_{i}^{*}=\sqrt{\frac{2 S D}{h P_{i}}}
$$

The result shows that the model developed is consistent with the classical EOQ model.

\subsection{Solution Algorithm}

The procedure for calculating the optimum quantity $\left(Q i^{*}\right)$ in equation (8) is:

Step 1. Calculate for each price break.

Step 2. Determine whether $Q_{i}{ }^{*}$, which has been calculated, is acceptable (valid). $Q_{i}{ }^{*}$ is valid if $Q_{i}{ }^{*}$ is at a predetermined $q$ interval.

Step 3. If $Q_{i}{ }^{*}$ is invalid ( $Q_{i}{ }^{*}$ is not at predetermined $q$ interval), then:

i. If $Q_{i}{ }^{*}$ is below the minimum threshold of $q_{i}$ interval, then $Q_{i}{ }^{*}$ should be $q_{i}$.

ii. If $Q_{i}{ }^{*}$ is above the minimum threshold of $q_{i}$ interval, then $Q_{i}{ }^{*}$ should be $q_{i+1}$

Step 4. Calculate $T C Q_{i}$ for each price break based on $Q_{i}{ }^{*}$ step 3.

Step 5. Compare $T C Q_{i}$, which are obtained, and choose it that gives the minimum $T C Q_{i}$.

Step 6. Calculate the $T E Q_{i}$ of the decision.

\section{NUMERICAL EXAMPLE}

An example is presented to illustrate the application of the model. The parameter values are mostly adopted from Gupta (1988) while for the parameters related to the emissions are from Wee \& Daryanto (2020), as follows:

$$
\begin{array}{ll}
h & =0.2 / \text { period } \\
D & =1000 \text { unit/period } \\
S & =\$ 10 / \text { order } \\
w & =1.44 \mathrm{kWh} / \text { unit } / \text { period } \\
E_{e} & =0.0005 \text { tonCO }_{2} / \mathrm{kWh} \\
F_{e} & =2.6 \mathrm{kgCO}_{2} / L=0.0026 \text { tonCO }_{2} / L \\
T_{x} & =\$ 75 / \text { tonCO } \\
d & =100 \mathrm{~km} \\
c_{1} & =27 \mathrm{~L} / 100 \mathrm{~km} \\
c_{2} & =0.57 \mathrm{~L} / 100 \mathrm{~km} / \text { truck load } \\
l & =0.01 \text { ton } / \text { unit } \\
t_{f} & =\$ 50 / \text { delivery } \\
t_{v} & =\$ 0.75 / L \\
e_{1} & =\$ 0.05265 / \mathrm{km} \\
e_{2} & =\$ 1.1115 \times 10^{-5} / \text { unit } / \mathrm{km}
\end{array}
$$

, while the discount price break is presented in Table 2.

Table 2. Price break

\begin{tabular}{|c|c|c|}
\hline $\boldsymbol{i}$ & $\boldsymbol{P}_{\boldsymbol{i}}$ & $\boldsymbol{q}_{\boldsymbol{i}}$ \\
\hline 1 & $\$ 5.00$ & 0 \\
\hline 2 & $\$ 4.75$ & 200 \\
\hline 3 & $\$ 4.50$ & 500 \\
\hline 4 & $\$ 4.20$ & 1000 \\
\hline 5 & $\$ 4.00$ & 2000 \\
\hline
\end{tabular}

Following the proposed procedure, the results are as follow:

Step 1. The calculations for each price break in Table 2 is $Q_{1}{ }^{*}=460$ units, $Q_{2}{ }^{*}=471$ units, $Q_{3}{ }^{*}=483$ units, $Q_{4}{ }^{*}=499$ units, $Q_{5}{ }^{*}=510$ units.

Step 2. Determine whether calculated $Q_{i}{ }^{*}$ could be accepted (valid). $Q_{i}{ }^{*}$ could be valid if $Q_{i}{ }^{*}$ is at a predetermined $q$ interval. Hence,

$Q_{1}{ }^{*}=460$ units (invalid),

$Q_{2}{ }^{*}=471$ units (valid),

$Q_{3}{ }^{*}=483$ units (invalid),

$Q_{4}{ }^{*}=499$ units (invalid),

$Q_{5}{ }^{*}=510$ units (invalid)

Step 3. Evaluate $Q_{i}{ }^{*}$ that is invalid. From the result above, then for $i=3,4,5$, the value of $Q_{i}{ }^{*}=$ $q_{i}$.

Step 4. Calculate $T C Q_{i}$ per year. Table 3 shows the results.

Step 5. Eventually, the optimal order $Q^{*}$ is 1000 units with $T C Q_{i}=\$ 4763.42$ per year. 
Step 6. The total carbon emission $\left(T E Q_{i}\right)$ resulted from the storage and transportation activities for each $i$ are shown in Table 4. For $Q^{*}=$ 1000 units then $T E Q_{i}=0.5152$ tonCO $\mathrm{CO}_{2}$ per year.

Table 3. The calculation results of $T C Q_{i}$

\begin{tabular}{|c|c|c|c|}
\hline $\boldsymbol{i}$ & $\boldsymbol{P}_{\boldsymbol{i}}$ & $\boldsymbol{Q}_{i}{ }^{*}$ & $\boldsymbol{T C Q}_{\boldsymbol{i}}$ per year \\
\hline 1 & $\$ 5.00$ & - & - \\
\hline 2 & $\$ 4.75$ & 471 & $\$ 5227.56$ \\
\hline 3 & $\$ 4.50$ & 500 & $\$ 4965.95$ \\
\hline 4 & $\$ 4.20$ & 1000 & $\$ 4763.42$ \\
\hline 5 & $\$ 4.00$ & 2000 & $\$ 4914.90$ \\
\hline
\end{tabular}

Table 4. The calculation of $T E Q_{i}(\operatorname{tonCO})_{2}$

\begin{tabular}{|c|c|c|c|c|}
\hline $\boldsymbol{i}$ & $\boldsymbol{Q}_{i}^{*}$ & $\begin{array}{c}\text { Storage } \\
\text { emissions }\end{array}$ & $\begin{array}{c}\text { Transportation } \\
\text { emissions }\end{array}$ & $\boldsymbol{T E Q _ { i }}$ \\
\hline 1 & - & - & - & - \\
\hline 2 & 471 & 0.1696 & 0.3129 & 0.4825 \\
\hline 3 & 500 & 0.1800 & 0.2956 & 0.4756 \\
\hline 4 & 1000 & 0.3600 & 0.1552 & 0.5152 \\
\hline 5 & 2000 & 0.7200 & 0.0850 & 0.8050 \\
\hline
\end{tabular}

Table 3 shows that the order quantity more reduces the total costs of inventory, except for $Q_{i}=2000$. If $Q_{i}$ $=2000$, storage costs will be doubled, and the total costs of inventory are higher. In this case, the savings obtained from price discounts, reduced ordering costs, and transportation costs are less than the increase in storage costs, including the carbon emission costs. Table 4 shows that the higher the order quantity, the more storage emissions increase while the transportation emissions decrease. The combination of storage and transportation emissions construct a convex function. For $i=3$, the $T E Q_{i}$ per year is $0.4756 \operatorname{tonCO}_{2}$ and becomes the smallest. However, it does not belong to the optimum $Q^{*}$ that gives minimum total cost.

\section{DISCUSSION}

This study takes data from Gupta (1988) as the basic numerical example. Table 5 provides a comparison. Similar to Gupta (1998), when the price decreases (due to higher discount), the calculated order quantity $Q_{i}$ increases. However, for each price schedule $i$, the result of $Q_{i}$ is higher when we consider transportation and emission costs. It means that the model is suggesting fewer transportation activities to reduce costs and emissions. Since there is a rule concerning the discount schedule, the optimum order quantity $Q_{i}{ }^{*}$ of this study is the same as Gupta (1988). Therefore, total emissions are also the same. Finally, as we can predict, the total inventory cost of this study is higher as we consider transportation and emission costs.

This study adds the effect of carbon emissions on the inventory decision model. Therefore a sensitivity analysis is conducted to study the impact of changes in carbon emission taxes on decisions made. The World Bank (2020) reported the application of carbon taxes in various countries up to $\$ 129$ per tonCO ${ }_{2}$, which was in Sweden. Therefore, sensitivity analyzes are carried out for several carbon tax values, from $\$ 0$ (no carbon tax) to $\$ 150$ per tonCO $\mathrm{C}_{2}$, assuming that the values of other parameters are fixed. Table 6 shows the results of the analysis.

Table 6. $T C Q_{i}$ and $T E Q_{i}$ for some values of $T_{x}$

\begin{tabular}{|c|c|c|c|}
\hline $\boldsymbol{T}_{\boldsymbol{x}}(\mathbf{\$})$ & $\boldsymbol{Q}^{*}$ & $\boldsymbol{T C} \boldsymbol{Q}_{\boldsymbol{i}} \mathbf{( \$ )}$ & $\boldsymbol{T E Q}_{\boldsymbol{i}}\left(\mathbf{t o n C O}_{\mathbf{2}}\right)$ \\
\hline 0 & 1000 & 4736.42 & 0.5152 \\
\hline 25 & 1000 & 4745.42 & 0.5152 \\
\hline 50 & 1000 & 4754.42 & 0.5152 \\
\hline 75 & 1000 & 4763.42 & 0.5152 \\
\hline 100 & 1000 & 4772.42 & 0.5152 \\
\hline 125 & 1000 & 4781.42 & 0.5152 \\
\hline 150 & 1000 & 4790.42 & 0.5152 \\
\hline
\end{tabular}

To study the comprehensive behavior of the inventory system, further sensitivity analysis is performed for the other parameters. It examines the effect of the changes on the storage cost percentage per period $(h)$, order costs $(S)$, mileage from the supplier $(d)$, fuel consumption when the vehicle is empty $\left(c_{1}\right)$, variable costs for shipping goods $\left(t_{v}\right)$, and the price per unit $\left(P_{i}\right)$ as the result of the changes on the discount rate, the decision variable $Q^{*}$, and the corresponding $T C Q_{i}$ and TEQi. The values change from $-50 \%$ to $+50 \%$, with an interval of $25 \%$. Table $7-12$ shows the results.

The results of the sensitivity analysis show that:

1) Changes in the level of carbon emissions do not change the optimum number of orders $Q$. It could happen because the discount factor of the number of orders provided benefits that got more attention from the company. However, from the examples given earlier, it reveals that the number of these orders gives the lowest level of emissions.

2) The greater the carbon emission tax with the same number of orders, the more the total cost will increase.

3) Total carbon emissions from storage and transportation activities are not sensitive to carbon emissions taxes. It is because the decision on the number of orders does not change.

Table 5. Comparison with Gupta (1988)

\begin{tabular}{|c|c|c|c|c|c|c|c|}
\hline & & \multicolumn{3}{|c|}{ Gupta (1988) } & \multicolumn{3}{|c|}{ This study } \\
\hline$i$ & $\boldsymbol{P}_{i}$ & $Q_{i}$ & & $\begin{array}{c}T C Q_{i} \text { per } \\
\text { year }\end{array}$ & $Q_{i}$ & n. & $\begin{array}{c}T C Q_{i} \text { per } \\
\text { year }\end{array}$ \\
\hline 1 & $\$ 5.00$ & 141.42 & 141.42 & $\$ 5141.42$ & 460 & - & - \\
\hline 2 & $\$ 4.75$ & 145.09 & 200 & $\$ 4895.00$ & 471 & 471 & $\$ 5227.56$ \\
\hline 3 & $\$ 4.50$ & 149.07 & 500 & $\$ 4745.00$ & 483 & 500 & $\$ 4965.95$ \\
\hline 4 & $\$ 4.20$ & 154.30 & 1000 & $\$ 4630.00$ & 499 & 1000 & $\$ 4763.42$ \\
\hline 5 & $\$ 4.00$ & 158.11 & 2000 & $\$ 4805.00$ & 510 & 2000 & $\$ 4914.90$ \\
\hline
\end{tabular}


Table 7. $T C Q_{i}$ and $T E Q_{i}$ for some values of $h$

\begin{tabular}{|c|c|c|c|c|}
\hline \% changes & $h$ & $Q^{*}$ & $T C Q_{i}(\$)$ & $T E Q_{i}\left(\operatorname{tonC} O_{2}\right)$ \\
\hline$+50 \%$ & 0.3 & 1000 & 4973.42 & 0.5152 \\
\hline$+25 \%$ & 0.25 & 1000 & 4868.42 & 0.5152 \\
\hline 0 & 0.2 & 1000 & 4763.42 & 0.5152 \\
\hline$-25 \%$ & 0.15 & 1000 & 4658.42 & 0.5152 \\
\hline$-50 \%$ & 0.1 & 1000 & 4553.42 & 0.5152 \\
\hline
\end{tabular}

Table 8. $T C Q_{i}$ and $T E Q_{i}$ for some values of $S$

\begin{tabular}{|c|c|c|c|c|}
\hline \% changes & $\boldsymbol{S}(\mathbf{\$})$ & $\boldsymbol{Q}^{*}$ & $\boldsymbol{T C \boldsymbol { Q } _ { i }} \mathbf{( \$ )}$ & $\left.\boldsymbol{T E Q _ { i } ( \mathbf { t o n C O }} \mathbf{2}\right)$ \\
\hline$+50 \%$ & 15 & 1000 & 4768.42 & 0.5152 \\
\hline$+25 \%$ & 12.5 & 1000 & 4765.92 & 0.5152 \\
\hline 0 & 10 & 1000 & 4763.42 & 0.5152 \\
\hline$-25 \%$ & 7.5 & 1000 & 4760.92 & 0.5152 \\
\hline$-50 \%$ & 5 & 1000 & 4758.42 & 0.5152 \\
\hline
\end{tabular}

Table 9. $T C Q_{i}$ and $T E Q_{i}$ for some values of $d$

\begin{tabular}{|c|c|c|c|c|}
\hline \% changes & $\boldsymbol{d}(\mathbf{k m})$ & $\boldsymbol{Q}^{*}$ & $\boldsymbol{T C \boldsymbol { Q } _ { \boldsymbol { i } } ( \mathbf { \$ } )}$ & $\left.\boldsymbol{T E \boldsymbol { Q } _ { \boldsymbol { i } } ( \mathbf { ( t o n C O }} \boldsymbol{2}\right)$ \\
\hline$+50 \%$ & 150 & 1000 & 4791.62 & 0.5152 \\
\hline$+25 \%$ & 125 & 1000 & 4777.52 & 0.5152 \\
\hline 0 & 100 & 1000 & 4763.42 & 0.5152 \\
\hline$-25 \%$ & 75 & 1000 & 4749.31 & 0.5152 \\
\hline$-50 \%$ & 50 & 1000 & 4735.21 & 0.5152 \\
\hline
\end{tabular}

Table 10. $T C Q_{i}$ and $T E Q_{i}$ for some values of $c_{1}$

\begin{tabular}{|c|c|c|c|c|}
\hline \% changes & $\boldsymbol{c}_{\boldsymbol{I}}(\mathbf{L} / \mathbf{k m})$ & $\boldsymbol{Q}^{\boldsymbol{*}}$ & $\boldsymbol{T C Q}_{\boldsymbol{i}} \mathbf{( \$ )}$ & $\boldsymbol{T E Q}_{\boldsymbol{i}}\left(\mathbf{t o n C \mathbf { O } _ { \boldsymbol { ~ } } )}\right.$ \\
\hline$+50 \%$ & 0.4050 & 1000 & 4791.62 & 0.5152 \\
\hline$+25 \%$ & 0.3375 & 1000 & 4777.52 & 0.5152 \\
\hline 0 & 0.2700 & 1000 & 4763.42 & 0.5152 \\
\hline$-25 \%$ & 0.2025 & 1000 & 4749.31 & 0.5152 \\
\hline$-50 \%$ & 0.1350 & 1000 & 4735.21 & 0.5152 \\
\hline
\end{tabular}

Table 11. $T C Q_{i}$ and $T E Q_{i}$ for some values of $t_{v}$

\begin{tabular}{|c|c|c|c|c|}
\hline \% changes & $t_{v}(\mathbf{L})$ & $Q^{*}$ & $T C Q_{i}(\$)$ & $T E Q_{i}\left(\operatorname{tonCO} \mathrm{C}_{2}\right)$ \\
\hline$+50 \%$ & 1.1250 & 1000 & 4785.80 & 0.5152 \\
\hline$+25 \%$ & 0.9375 & 1000 & 4774.61 & 0.5152 \\
\hline 0 & 0.7500 & 1000 & 4763.42 & 0.5152 \\
\hline$-25 \%$ & 0.5625 & 1000 & 4752.22 & 0.5152 \\
\hline$-50 \%$ & 0.3750 & 1000 & 4741.02 & 0.5152 \\
\hline
\end{tabular}

4) If the storage cost percentage per period, order costs, and variable costs for shipping goods increase, the total cost increases while the total carbon emissions do not change.

5) If the mileage from the supplier and fuel consumption of empty vehicle increase, then both the total cost and total carbon emissions increase.

6) If the discount rate, which will reduce the price per unit, increases, the total cost decreases. Furthermore, the optimum order quantity and total emissions increase when the discount rate increases by $50 \%$. Hence, at a certain point, the discount rate harms the environment.
7) The total cost is more sensitive to the changes in storage cost percentage per period and price per unit. 
Table 12. $T C Q_{i}$ and $T E Q_{i}$ for some values of $P_{i}$

\begin{tabular}{|c|c|c|c|c|}
\hline \% changes* & $\boldsymbol{P}_{i}(\$)$ & $Q^{*}$ & $T C Q_{i}(\$)$ & $\left.T E Q_{i}(\operatorname{tonCO})_{2}\right)$ \\
\hline$+50 \%$ & $\begin{array}{l}P 1=5.00 \\
P 2=4.625 \\
P 3=4.25 \\
P 4=3.80 \\
P 5=3.50\end{array}$ & 2000 & 4314.90 & 0.8050 \\
\hline$+25 \%$ & $\begin{array}{l}P 1=5.00 \\
P 2=4.6875 \\
P 3=4.375 \\
P 4=4.00 \\
P 5=3.75\end{array}$ & 1000 & 4543.42 & 0.5152 \\
\hline 0 & $\begin{array}{l}P 1=5.00 \\
P 2=4.75 \\
P 3=4.5 \\
P 4=4.20 \\
P 5=4.00\end{array}$ & 1000 & 4736.42 & 0.5152 \\
\hline$-25 \%$ & $\begin{array}{l}P 1=5.00 \\
P 2=4.8125 \\
P 3=4.625 \\
P 4=4.40 \\
P 5=4.25\end{array}$ & 1000 & 4983.42 & 0.5152 \\
\hline$-50 \%$ & $\begin{array}{l}P 1=5.00 \\
P 2=4.875 \\
P 3=4.75 \\
P 4=4.60 \\
P 5=4.50\end{array}$ & 1000 & 5203.42 & 0.5152 \\
\hline
\end{tabular}

*Changes on the discount rate

\section{CONCLUSION}

This research presents an inventory model considering an all-unit discount and carbon emissions simultaneously. It assumes that the manufacturer works in a country implementing a carbon tax system and is willing to be greener. This model could help the purchasing manager in determining the optimum order quantity. A numerical example is provided to illustrate the effectiveness of the model by adopting data from Gupta (1988) and Wee \& Daryanto (2020). For each discount schedule $i$, the result of $Q_{i}$ is higher when we consider transportation and emission costs. Since there is a rule concerning the discount schedule, the optimum order quantity $Q_{i}{ }^{*}$ of this study is the same as Gupta (1988). The numerical example also identifies that the optimum order quantity giving minimum total costs do not guarantee minimum total emissions. Moreover, the sensitivity analysis shows that the total emissions are not sensitive to the changes in the carbon tax rate when a discount schedule is applied. At a certain point, the discount rate harms the environment.

Nevertheless, this model still has specific weaknesses that could be refined for further researches. The present study only works for all-unit discounts. Hence, future research may consider other discount schemes. Future studies could also consider the limitations of warehouse capacity as in Widodo \& Utama (2019) and the effect of low quality (Wee \& Daryanto, 2020).

\section{REFERENCES}

Benjaafar, S., Li, Y. \& Daskin, M. (2013). Carbon footprint and the management of supply chains: Insights from simple models. IEEE Transactions on Automation Science and Engineering, 10, 99-116.

Bonney, M. \& Jaber, M. (2011). Environmentally responsible inventory models: Non-classical models for a non-classical era. International Journal of Production Economics. 133. 43-53.

Chen, X., Benjaafar, S. \& Elomri, A. (2013). The carbon-constrained EOQ. Operations Research Letters. 41. 172-179.

Daryanto, Y., Wee, H.M. \& Widyadana, G.A. (2019). Low carbon supply chain coordination for imperfect quality deteriorating items. Mathematics, 7 (3), 234.

Djunaidi, M., Nadiroh, S. \& Marzuki, I. O. (2005). Pengaruh perencanaan pembelian bahan baku dengan model EOQ untuk multiitem dengan all unit discount. Jurnal Ilmiah Teknik Industri, 4, 86-94.

Gupta, O.K. (1988). An improved procedure for economic order quantity with all-units price discounts. International Journal of Operations \& Production Management, 8, 79-83.

Gupta, O.K. (1992). A lot-size model with discrete 
transportation costs. Computers \& Industrial Engineering, 22 (4), 397-402.

Hovelaque, V. \& Bironneau, L. (2015). The carbonconstrained EOQ model with carbon emission dependent demand. International Journal of Production Economics, 164, 285-291.

José, L.A. \& García-Laguna, J. (2003). An EOQ model with backorders and all-units discounts. TOP: An Official Journal of the Spanish Society of Statistics and Operations Research, 11, 253-274.

Kazemi, N., Abdul-Rashid, S.H., Ghazilla, R.A.R., Shekarian, E. \& Zanoni, S. (2018). Economic order quantity models for items with imperfect quality and emission considerations. International Journal of Systems Science: Operations \& Logistics, 5 (2), 99115.

Limansyah, T. \& Lesmono, D. (2011). Model persediaan multi item dengan mempertimbangkan faktor kedaluwarsa dan faktor all unit discount. Jurnal Teknik Industri, 13 (2), 87-94.

Swenseth, S.R. \& Godfrey, M.R. (1992). Incorporating transportation costs into inventory replenishment decisions. International Journal of Production Economics, 77, 113-130.

Taleizadeh, A.A. \& Pentico, DW. (2014). An economic order quantity model with partial backordering and all-units discount. International Journal of Production Economics, 155, 172-184.
Tao, Z. \& Xu, J. (2019). Carbon-regulated EOQ models with consumers' low-carbon awareness. Sustainability, 11 (4), 1004.

Tersine, R.J. (1994). Principles of Inventory and Materials Management, $4^{\text {th }} e d$. Prentice-Hall International, Inc: New Jersey.

Wang, S. \& Ye, B. (2018). A comparison between justin-time and economic order quantity models with carbon emissions. Journal of Cleaner Production, $187,662-671$

Wangsa, I.D. \& Wee, H.M. (2020). Integrated inventory system with freight costs and two types of quantity discounts. International Journal of Logistics Systems and Management, 35 (1), 119-147.

Wee, H.M. \& Daryanto, Y. (2020). Imperfect quality item inventory models considering carbon emissions. In Shah, N.H. \& Mittal, M. (eds.) Optimization and Inventory Management. Singapore: Springer Nature, pp 137-159.

Widodo, D.S. \& Utama, D.M. (2019). Analisis model sustainable economic order quantity dengan mempertimbangkan emisi karbon dan batasan kapasitas gudang untuk menekan total biaya persediaan. Teknik, 40 (3), 169-175

World Bank (2020). Carbon pricing dashboard. Retrieved from carbonpricingdashboard.worldbank.org/ 